\title{
O ESTATUTO TEMPORAL E SOCIAL DO SIGNO
}

Ricardo Gião BORTOLOTTI ${ }^{1}$

- RESUM 0: Este trabalho tem como objetivo mostrar como o processo de conhecimento traduz-se numa estrutura triádica, cuja característica não pode prescindir da temporalidade e de seu aspecto social. De outra forma, conforme 0 dualismo subjacente nas teorias tradicionais, a esfera do conhecimento tornar-se-ia limitada pela inevitabilidade do recurso à coisa-em-si.

- PALAVRAS-CHAVE: Cognição; conhecimento; signo; pensamento; significado; comunidade; semiose.

\section{Introdução}

A explicação nominalista do processo de conhecimento, ao sugerir uma visão dual deste processo, impede-nos de observá-lo no dinamismo próprio de uma inteligência que cresce no tempo. A visão dual, característica do pensamento moderno, concebe a mente como um mero receptáculo das impressões sensoriais, de forma mecânica e estática. Tal concepção não nos parece adequada a uma inteligência que aprende, a qual não se caracteriza pela atemporalidade, mas, ao contrário, é no desdobrar-se do tempo que o conhecimento se efetiva. A ceitar a relação estática sujeito/objeto, como o fundamento do processo de conhecimento, é dar crédito a uma forma repetitiva e neurótica de acessar a tradição, resistindo às mudanças e à criação.

1 Departamento de História - Faculdade de Ciências e Letras - UNESP - 19800-000 - Assis - SP - Brasil. 
A proposta peirceana rompe com a visão tradicional, ao propor uma concepção triádica do processo de conhecimento. A peculiaridade de tal concepção está no dinamismo que confere à consciência, no desenvolvimento daquele processo. Com a noção peirceana de signo, as formas do passado, presente e futuro apresentam-se em contínua interação, resultando num movimento criativo, cujo produto quase sempre não se esgota numa única relação, mas se abre a possibilidades infinitas.

Aceitando-se essa concepção do processo de conhecimento, evita-se todo tipo de individualismo que, porventura, possa dominar o âmbito do pensamento. Este último, ao constituir-se de signos, mostra-se predominantemente social: ao projetar-se no futuro, o pensamento retoma o passado, universo da tradição, reproduzindo um outro pensamento mais desenvolvido. 0 indivíduo em si, seja em sua interioridade ou na esfera institucional, jamais está só, mas dialoga com a comunidade de seres pensantes, a qual representa o universo de informações alcançadas até o presente.

0 presente artigo tem como objetivo apresentar como o signo, e, com ele, o conhecimento, consistem num processo dinâmico, temporal, e que só podem ser compreendidos em seu aspecto social. Para isso, partimos de algumas considerações acerca da teoria da cognição, em Peirce, a fim de que o leitor possa se inteirar a respeito do processo de pensamento peirceano, importante para a compreensão de toda sua doutrina. Em seguida, expomos a definição de signo e seu caráter temporal, um desdobramento de seu processo cognitivo, pensado em sua estrutura triádica. Por fim, discutimos o aspecto social do signo e do próprio conhecimento, aspecto que interessa à validez do processo cognitivo.

\section{0 processo cognitivo}

A concepção peirceana do processo de conhecimento baseia-se na teoria da cognição, exposta nos textos de 1868-1871. Essa teoria funda-se numa concepção triádica de apreensão do conhecimento, contrariando as teorias modernas, como as elaboradas por Descartes, Berkeley e Kant. 0 intuicionismo, o ideal ismo subjetivo e o transcendentalismo deixam a desejar, ao explicarem o processo do conhecimento por meio de um esquema dual de apreensão da realidade, que pressupõe o incognoscível.

Essas teorias, rotuladas de nominalistas por Peirce, ao pressuporem a cisão sujeito/objeto, concebem o conhecimento como um processo em que a mente apreende o objeto de forma mecânica e estática, sem referência à temporalidade. Nessa perspectiva, o conhecimento se reduz a 
um mero processo de denotação do objeto pelo sujeito, carecendo de caráter dinâmico e de constante interação com o novo, próprios de uma inteligência que aprende.

A consciência é vista, pois, como um receptáculo, que recebe os efeitos das coisas externas (A pel, 1981, p.25). Estas últimas permanecem, como coisas-em-si, incognoscíveis, enquanto o conhecimento se restringe ao âmbito da "substância pensante". Com efeito, a apreensão do conhecimento torna-se imediata, resultante de inferências derivadas de um processo intuitivo. Ora, Peirce não só condena a intuição, como também não aceita a existência de algo incognoscível. Para ele, "o nãocognoscível, se conceito, é um conceito da forma 'A, não- $A$ ', e é, pelo menos, autocontraditório" (CP-5.257). ${ }^{2}$

A origem do conhecimento, explicada a partir de primeiras premissas, sejam elas intuídas à maneira cartesiana, ou a partir de princípios a priori, como deparamos em Kant, limita o alcance do conhecimento. É com o intuito de abordar o processo de conhecimento, como um processo de aprendizagem que não se aproxima do nominalismo, que Peirce define a cognição, como consistindo de um processo inferencial, cujo fundamento repousa na tríade sígnica (CP-5.220 s.).

Encontramos, ao longo de seu trabalho, vários exemplos contrários ao conhecimento imediato (CP-5.219 s.). Vejamos um deles:

A altura de um tom depende da rapidez da sucessão das vibrações que atingem o ouvido. Cada uma dessas vibrações produz um impulso singular desse tipo sobre o ouvido. Produza-se um impulso singular desse tipo sobre o ouvido e sabemos, experimentalmente, que ele é percebido. Portanto, há um bom motivo para crer que cada um dos impulsos que forma um tom é percebido. Nem há razão para que assim não seja. De modo que esta é a única suposição admissível. Portanto, a altura de um tom depende da rapidez com que certas impressões são sucessivamente transmitidas para a mente. Estas impressões devem existir anteriormente a qualquer tom; por conseguinte, a sensação da altura é determinada por cognições prévias. Não obstante, isto jamais seria descoberto através da mera contemplação daquela sensação. (CP-5.222)

Com esse exemplo, o autor pretende mostrar que nossas cognições são frutos de cognições anteriores, perfazendo, a consciência, uma cadeia inesgotável de pensamentos, num tempo finito (CP-5.253 e 263). A intuição, ao contrário, revela-nos um primeiro princípio que coordenaria todo

2 CP indica Collected Papers, e se refere à obra de Hartshorne. 0 primeiro número corresponde ao volume e o segundo ao parágrafo. 
fluxo posterior do pensamento. Essa noção do processo mental não é, com efeito, válida, já que a única explicação plausível para o aparecimento dos primei ros princípios teria de contar com o poder divino (Gallie, 1975, p.63).

Vê-se logo 0 entrave que a aceitação do conhecimento imediato resultaria: limitaria o âmbito do conhecimento, abrindo espaço para a coisa-em-si (CP-5.213 e Murphey, 1961, p.106-7). Ora, a proposta peirceana devolve à filosofia sua antiga ambição de atingir o absoluto, propondo uma teoria que descarta qualquer separação entre uma mente, que conhece, e uma realidade a ela inatingível. Não há tal coisa; conhecemos a realidade por se tratar de uma representação que integ ra o contínuo do pensamento, constituindo seu objeto no desdobrar-se do pensamento no tempo.

Essa posição, 0 autor a defende desde, pelo menos, 1861, quando substitui a síntese da apercepção kantiana por uma operação inferencial (A pel, 1981, p.39). A partir daí, o silogismo passa a ser a operação que define o processo de pensamento: "alguma coisa ... toma o lugar no organismo que equivale ao processo silogístico" (CP-5.268). Esse processo não se reduz, no entanto, a meras combinações sintáticas de símbolos vazios de conteúdo, mas se refere às relações reais com o mundo exterior ao pensamento (CP-5.244 s. e 267). 0 mesmo pode ser mantido em relação ao que denominamos mundo interno:

a sensação de vermelhidão é aquilo que é, em razão da constituição da mente, e neste sentido é uma sensação de algo interno. Por conseguinte, podemos derivar um conhecimento da mente a partir de uma consideração desta sensação, mas esse conhecimento seria, de fato, uma inferência da vermelhidão como sendo um predicado de algo externo. (CP-5.245)

Assim, o conhecimento que alcançamos é produto de inferências, derivadas do mundo exterior. 0 processo inferencial não parte de um princípio, mas se desdobra em inúmeras premissas, sem se esgotar numa primeira. Essa indeterminação é própria do processo cognoscível peirceano, e podemos constatá-la pela da leitura dos CP-5.263:

refazendo nosso percurso a partir das conclusões para as premissas, ou a partir de cognições determinadas para as que as determinam, chegamos, em todos os casos, a um ponto além do qual a consciência na cognição determinada é mais vivida do que na cognição que a determina. Temos uma consciência menos vivida na cognição que determina nossa cognição da terceira dimensão do que nesta última cognição; uma consciência menos vivida na cognição que determina nossa cognição de uma superfície contínua (sem um ponto cego) do que nesta última cognição; e uma consciência menos vivida das impressões que determinam a sensação de tom do que nessa própria. De fato, quando chegamos suficientemente perto do mundo externo esta é a regra universal. 
A impossibilidade de chegarmos a uma primeira cognição mostra-nos que os elementos da cognição são gerais, e só a eles temos acesso. Os signos ou as concepções que perfazem a cadeia cognitiva não se caracterizam por apenas denotarem o objeto, apresentando-se, assim, como meros nomes. São, na verdade, representações gerais, cuja peculiaridade consiste em replicarem o número de representações ad infinitum.

Peirce sempre enfatizou o caráter real de nossas concepções, acentuando com firmeza sua preferência pelo realismo, em detrimento do nominal ismo, que defende serem os signos meros nomes. Para o nominalista, há apenas uma única realidade, a qual é absolutamente determinada e individual. 0 realismo peirceano, ao contrário, baseia-se na indeterminação do produto da cognição:

visto que nenhuma cognição nossa é absolutamente determinada, universais devem ter uma existência real. Agora, esse realismo escolástico é usualmente expresso como uma crença em ficções metafísicas. Mas, de fato, um realista é simplesmente alguém que não conhece uma recôndita realidade mais do que aquela que é representada em uma representação verdadeira. Visto que, portanto, a palavra "homem" é verdadeira de alguma coisa, aquilo que "homem" significa é real. 0 nominalista deve admitir que homem é verdadeiramente aplicável a alguma coisa; mas ele acredita que há abaixo disso uma coisa-emsi, uma realidade incognoscível. Dele é a ficção metafísica. (CP-5.312; cf. também OS CP-8.14)

Como resultado da noção de cognição, o indivíduo ou o existente, em sua absoluta determinação, somente pode ser concebido em sua forma potencial, indeterminada. 0 existente, que é considerado a mola propulsora do pensamento, é apreendido pelo ato de atenção que lhe confere uma qualidade, verificada ao longo do tempo. Nesse processo, a cadeia de inferências atinge níveis de generalidade cada vez mais crescentes, sendo ilusório pensar que uma representação possa esgotar o processo, a ponto de corresponder a seu elemento mais simples.

0 real ismo peirceano mantém que nossas concepções gerais são tão reais quanto o mundo concreto. 0 real, no entanto, é conhecível por meio de um processo de interpretação que se estende ao longo do tempo e jamais se esgota na individualidade do existente. 0 fato de nossas concepções corresponderem ao objeto externo significa que as opiniões, alcançadas com o passar do tempo, não contrariaram as impressões que obtivemos dele.

Essa relação do real, que equivale à cadeia de pensamentos, é exposta em maiores detalhes nos CP-5.316: 
como o que alguma coisa realmente é, é o que pode finalmente chegar a ser conhecida como o estado ideal de completa informação, de modo que a realidade depende da última decisão da comunidade; assim o pensamento, que é o que é, apenas por virtude de seu endereçar-se ao pensamento futuro, o qual é em seu valor (value) como pensamento, idêntico a ele, embora mais desenvolvido. Desse modo, a existência do pensamento agora depende do que virá; de modo que ele tem uma existência potencial, dependente do futuro pensamento da comunidade.

Notamos, pela leitura dos CP-5.316, que a noção de cognição peirceana mantém-se consistente, ao abordar a noção de realidade. Não entraremos em detalhes quanto a esta última noção; ressaltamos, porém, seu aspecto não-individual, o qual corresponde perfeitamente à proposta peirceana do processo cognitivo. A noção de comunidade confere um caráter social às nossas representações, estando também aberta à indeterminação do futuro. Em outros termos, a realidade não corresponde à opinião individual, cristalizada num tempo finito, mas ao "estado ideal de completa informação", alcançado, com o passar do tempo, pela comunidade de seres pensantes. Retornaremos a ela mais à frente.

Com o intuito de sumarizar o que discutimos até o momento, podemos dizer que a noção de cognição peirceana, além de se opor ao imediatismo do cartesianismo e ao transcendentalismo, opõe-se, também, a qualquer doutrina que não consiga explicar as várias modalidades do real. Em outros termos, a concepção de cognição de Peirce possibilita, por meio de seu caráter processual, temporal, o conhecimento da realidade em seus modos de representação. Estes últimos, por sua vez, interagem entre si perfazendo uma relação triádica, apreendida na representação-sígnica.

Ora, se não temos acesso aos primeiros princípios, por meio da intuição, e tampouco conseguimos alcançar o conhecimento, pela da análise introspectiva, já que todo nosso conhecimento provém do mundo exterior, resta-nos, pois, o conhecimento proveniente do desenrolar sígnico. Com efeito, nossos pensamentos são pensamentos em signos, como bem afirma Peirce nos CP-5.251. A análise do signo é a única que pode apresentar o caráter processual e temporal, próprios do trabalho de uma mente que aprende.

\section{Signo e temporalidade}

O signo, usado por Peirce, para dar conta de todo processo de conhecimento, juntamente com os termos "representação" e "pensamen- 
to" (CP-1.538; 5.251, 253, 283), não se identifica com as definições comumente utilizadas e que se caracterizam pela relação binária (significante e significado, expressão e conteúdo, imagem mental e imagem sensível etc.) (Silveira, p.7-8). Essas definições não o abordam em sua dimensão temporal, histórica, já que operam por oposição de ambas as partes, como expõe Silveira (p.14), a propósito da Semiologia de Saussure:

0 signo lingüístico é a relação socialmente estabelecida entre uma imagem acústica e uma imagem mental, ambas capazes de exercer seu papel específico no interior da língua, dado que suas realizações se diversificam pura e simplesmente por oposição recíproca. A língua não precisa recorrer à sua história para determinar que signos usar e que significados veicular: um signo significará na medida em que sua imagem acústica, que exerce a função de significante, se opuser a todas as outras imagens acústicas e recortar uma imagem mental igualmente oposta a todas as outras.

A estrutura do signo peirceano possibilita a interação do passado, presente e futuro, conferindo à cognição a característica processual, própria da mente que aprende. ${ }^{3} 0$ signo, de caráter binário, não representa o processo cognitivo satisfatoriamente, pois não diferencia aqueles três momentos, apresentando suas relações congeladas no presente. A noção de Peirce, ao contrário, baseia-se num processo contínuo de apreensão do passado pelo presente, em vista de sua projeção no futuro.

Esses três momentos estão correlacionados nas três referências do signo expostas em CP-5.283, um dos vários tex tos em que Peirce discute essa noção (CP-1.339, 538 s.; 2.228, 274, 303; 5.):

um signo tem, como tal, três referências: primeiro, é um signo para algum pensamento que o interpreta; é um signo de algum objeto ao qual, naquele pensamento, é equivalente; terceiro, é um signo, em algum aspecto ou qualidade, que o põe em conexão com seu objeto.

O signo representa, pois, seu objeto, para uma mente interpretante, ou corresponde a um outro signo, sob algum aspecto ou qualidade. Estes três correlatos são também denominados, pelo autor, de representamen, objeto e interpretante. ${ }^{4}$

3 "Uma inteligência que pode aprender com a experiência é uma inteligência que pensa no tempo. Para ela, o pensamento é intrinsecamente processo, é irredutivelmente histórico" (Silveira, 1983, p.15).

4 "Um Signo, ou Representamen, é um Primeiro que se coloca numa relação triádica genuína tal com um Segundo, denominado seu Objeto, que é capaz de determinar um Terceiro, denominado seu 
Embora a complexidade da discussão em torno do processo semiótico tenha aumentado, com o desenvolvimento do pensamento peirceano, inserindo-se, na discussão, as categorias de sua fenomenologia, o que nos interessa, no momento, é esclarecer a relação das propriedades do signo com a noção de temporalidade.

A primeira característica do signo, a ressaltar, diz respeito a sua qualidade material. É a representação, tomada em si mesma, sem relação a qualquer pensamento subseqüente; uma palavra, por exemplo, apresenta-se, de imediato, com um número de letras desenhadas numa folha de papel. Neste caso, sobressaem as qualidades que fazem da representação o que ela é, materialmente, à imediatidade do olhar.

A segunda característica do signo consiste em sua relação com o objeto. Essa relação constitui uma relação real, ou seja, um signo deve estar ligado a seu objeto em realidade. Em outros termos, deve haver uma conexão física entre ambos, como, por exemplo, a que observamos num indicador da posição do vento, o cata-vento. Nesse caso, o signo que representa a direção do vento é o próprio objeto que significa (significs) (CP-5.287).

$\mathrm{Na}$ tríade sígnica, o objeto aparece como o outro, consistindo sua apreensão, no âmbito da consciência, uma ação da atenção. Essa ação envolve uma espécie de conflito entre um ego e um não-ego; um esforço por parte da consciência em apreender aquilo que a afeta, do exterior. Isso que a afeta é, com efeito, independente de sua ação, é o fato acabado, o qual determina o signo no processo cognitivo.

A terceira característica do signo consiste em sua capacidade de endereçar-se a uma mente interpretante, ou em sua função representativa. Trata-se da produção de um outro pensamento, mediador da relação do signo ou representamen e do objeto. Esse pólo da tríade sígnica representa a cognição propriamente dita, no que concerne à continuidade do pensamento. Em si mesmo, o pensamento se reduz à sua qualidade material, destituído de sentido. Ele passa a significar (means), à medida que se conecta a outro pensamento no tempo (CP-5.253, 284).

$A$ ação da mente que interpreta constitui, na verdade, a essência do signo, como bem afirma Peirce, nos CP-5.253:

Da proposição de que todo pensamento é um signo, segue-se que todo pensamento deve endereçar-se a algum outro pensamento, deve determinar algum outro pensamento, uma vez que essa é a essência do signo.

Interpretante, que assuma a mesma relação triádica com seu Objeto, na qual ele próprio está em relação com o mesmo objeto" (CP-2.274; cf. também, os CP-2.228, 303) 
0 pensamento está, portanto, em signos, e somente pode ser conhecido à medida que se refere a seu objeto, segundo sua própria essência, que é a de endereçar-se a um outro signo. Ao tornar, pois, o mundo um signo de si próprio, tal processo mostra-nos que o presente imediato nada revela, a não ser o produto de infinitos instantes.

0 "valor intelectual" de um signo ou seu significado (meaning) jaz, pois, em seu futuro interpretante. É a propriedade do signo em comunicar-se com outro, no tempo, que o torna uma representação de alguma coisa. A carência de temporalidade impede que o signo se apresente como evolutivo, deixando de mostrar a riqueza de informações que 0 acúmulo do tempo Ihe proporcionou. 0 significado (meaning) de "eletricidade", por exemplo, não se esgotaria na apreensão atual do objeto eletricidade, mas, pelo contrário, uma cadeia de interpretantes apresentar-se-ia como determinações de potencialidades, que, com o tempo, poderiam realizar-se.

Essa orientação para o futuro, peculiar à essência do pensamento, mostra-nos quanto Peirce é avesso a qualquer espécie de imediatismo. Deparamos com vários exemplos no transcorrer de sua obra, em que ele condena a cristalização do tempo no presente imediato. A atualidade, separada do contínuo temporal, não apresenta o movimento da inteligência que aprende. Isso pode ser evidenciado por meio da noção de significado pragmático do signo; colhido do texto "How to make our ideas clear", de 1878:

Considerar que efeitos - imaginavelmente possíveis de alcance prático concebemos que possa ter 0 objeto de nossa concepção. A concepção desses efeitos corresponderá ao todo da concepção que tenhamos do objeto. (CP-5.402)

Essa máxima sugere que o significado (meaning) de uma concepção implica um experimento mental. Um experimento em que o resultado factual não consiste no ato fundamental, o qual forneceria a razão de ser do significado (meaning) da concepção. Obviamente, 0 aspecto sensorial se manifesta, já que o objeto da concepção "existe", em razão de seus efeitos. 0 significado (meaning) se caracteriza, no entanto, pela soma dos efeitos imaginados (ou concebíveis) do objeto da concepção, e sua verdade consiste na crença, constantemente reafirmada, de que as irradiações sensoriais correspondem a nossas projeções futuras.

Sob essa noção de significado, uma concepção ou proposição é esclarecida por uma outra concepção ou proposição, a qual proporciona um grau maior de inteligibilidade à concepção passada. 0 próprio cará- 
ter processual do pensamento confere inteligibilidade à concepção passada, ao desdobrá-la em uma série de concepções, que representam os possíveis efeitos de seus objetos. Assim procedendo, as determinações do passado são retomadas no presente, com vistas a novas formas de se relacionarem, possibilitando a modificação da conduta, ou repetição dos modos de ação, mantidos pela tradição.

A determinação de novas condutas ou a repetição do antigo padrão dependem das condições estipuladas pelos interpretantes futuros. 0 significado (meaning) de "duro", por exemplo, consiste no fato de seu objeto jamais ser riscado (CP-5.403). Essa condição não se esgota em um experimento atual, mas se mantém, mesmo que não haja experimento para testá-la. Assim, o conhecimento de algo duro depende da possibilidade de ele não ser riscado com o passar do tempo.

A conduta modificar-se-ia, caso a crença na dureza do objeto fosse contrariada por um experimento. Com isso, a interação do passado no processo triádico de pensamento não se coadunaria com a conduta esperada, gerando dúvidas quanto à verdade do signo ou da representação. 0 pensamento ver-se-ia estimulado a buscar uma nova opinião, traçando novos modos de ação perante o objeto. Em outros termos, o processo de pensamento determinaria novas cadeias de interpretantes, representando os efeitos possíveis do objeto em questão.

Assim, por meio do significado pragmático do signo, notamos que a essência do pensamento consiste em projetar-se no futuro. É essa característica que o distingue das concepções propostas pelas teorias tradicionais, as quais aceitam a explicação do processo de conhecimento, conforme uma filosofia da consciência, baseada na noção da mente como um receptáculo. Com a noção peirceana, a intenção e a conduta, determinadas pelo objeto do signo, são integradas na tríade evolutiva, possibilitando à mente, que pensa, a previsão e o controle de sua conduta perante os concebíveis efeitos do objeto.

\section{0 estatuto social do signo}

Peirce, ao dar conta do processo de conhecimento, pela intermediação sígnica, renega qualquer tipo de individualismo no âmbito do pensamento. A essência do pensamento é a de endereçar-se ao pensamento futuro, o qual não se esgota na finitude do indivíduo, mas permanece aberto a novas configurações. Isso somente é possível a partir da perspectiva de uma comunidade de seres que pensam por meio de signos. 
0 individualismo sempre fora condenado por Peirce, que via nele a fonte do erro e da ignorância:

O homem individual, visto que sua existência separada manifesta-se apenas pela ignorância e o erro, posto ser algo afastado de seus companheiros; e do que ele e seus companheiros possam ser, é apenas uma negação. (CP-5.317)

Em Questions Concerning Certain Faculties Claimed For Man, artigo de 1868, Peirce atribui o erro ao eu privado: "A ignorância e o erro são tudo aquilo que distingue nosso eu privado do ego absoluto da pura apercepção" (CP-5-235). Vê-se, pois, que a verdade somente pode ser admitida na esfera mais ampla de uma comunidade. 0 testemunho generalizado, representado pela comunidade, é, pois, a única via de acesso à verdade. À quele que contrariar essa via, teimando em agir conforme sua subjetividade, resta apenas a ilusão.

Num outro texto de 1868, intitulado Grounds of Valid ity of the Laws of Logic, Peirce apresenta-nos o pensar de acordo com a comunidade, como sendo a única forma de comportamento racional. Constitui uma necessidade lógica 0 abandono de nossos interesses individuais em prol dos interesses mais amplos da comunidade. Dessa forma, é o indivíduo que passa a confiar nos princípios do silogismo e sacrifica sua crença particular, esperando que a corrente de pensamentos que o indentifica com a maioria atinja a última opinião acerca do real, garantindo, assim, a validade lógica de seus pensamentos (CP-5.354 s.).

A "maioria", aqui aludida, não se refere a um grupo que mantém à força uma determinada crença sobre os demais. Na verdade, quer o texto dizer que o indivíduo sacrifica o caráter ilusório de suas crenças individuais, passando a considerar o testemunho generalizado, o qual se mantém ao longo do tempo. Tal testemunho encontra-se cristalizado pela tradição, a operar nos raciocínios silogísticos, cujos princípios servem a todos os seus usuários. $^{5}$

0 indivíduo deve, portanto, tornar sua crença mais segura, cedendo à experiência do tempo, que elimina o erro e a ignorância, apresentando, como resultado, apenas o que resiste à opinião particular. Tal eliminação do erro e da ignorância possibilita que a crença que permanece seja identificada com a crença da comunidade.

5 A identificação do raciocínio silogístico com o processo mental pode ser vista nos CP-5.268-269 e 279. 
Assim, a verdade não se limita às opiniões individuais, que possuem um tempo finito, esgotando-se o conhecimento em cognições atuais; nem mesmo, a uma comunidade limitada, pois esta estaria à mercê do acaso, que a extinguiria sem que o conhecimento fosse alcançado (CP-5.357). Pode-se dizer, portanto, que ela significa, nesse contexto, a esperança de que a investigação, definida em termos da teoria da cognição, atinja seu destino (Ibidem).

Cabe ainda uma ressalva em relação à noção de comunidade. Embora Peirce, no início dos Some Consequences of Four Incapacities, texto elaborado em 1868, proponha uma "comunidade de filósofos", a fim de fazer frente à consciência individual, de Descartes (CP-5.265), tal noção não se reduz à esfera limitada dos seres humanos. Ao contrário, ele se refere à união de mentes habilitadas a pensarem por meio de signos. Essa característica ilimitada da comunidade pode ser inferida, além de sua conhecida aversão por qualquer tipo de individualismo, da leitura da resenha de Berkeley, de 1871. Nesta, ele afirma:

o consenso católico que constitui a verdade não deve, de modo algum, ser limitado ao homem nesta vida terrena ou à raça humana, mas estender-se a toda comunhão de mentes a que pertencemos, incluindo algumas, provavelmente, cujos sentidos são bem diferentes dos nossos... (CP-8.13)

Esclarecidas a rejeição de Peirce pelo individual ismo e sua preferência pelo aspecto social do pensamento, resta-nos explicitar a relação de tal aspecto com o signo.

O signo tem uma estrutura triádica, cabendo a função representativa ao interpretante. Este representa o pensamento futuro, um outro signo determinado por seus dois correlatos. Ora, o pensamento ou signo, que surge no tempo, não é fruto de um pensamento isolado; pelo contrário, é considerado verdadeiro, conforme se apresenta como resultado de uma cadeia de raciocínios, elaborada pela comunidade. Esta última, por sua vez, não apenas valida o pensamento passado, o qual já se encontra integrado nela, mas, segundo as normas do silogismo, o pensamento futuro deve corresponder à verdade, mantida pela comunidade.

0 caráter unificador do raciocínio pode ser visto, em 1873, época em que Peirce define a investigação científica, consistindo de observação e de raciocínio (CP-7.327-335). Para ele, a observação consiste no resultado da ação do mundo exterior, que influencia as sensações. Ao raciocínio, por sua vez, cabe separar e unir as diversas idéias originadas daquele processo (CP-7.335). 
As sensações apreendidas, no ato da observação, são integ radas numa opinião coerente com a opinião mantida pela comunidade. Podemos dizer que, nesse âmbito, encontramo-nos diante do objeto do signo, que se apresenta como o passado. A semiose, no entanto, não se esgota na apreensão do passado; ao contrário, o significado (meaning) do signo remetenos ao futuro. A opinião mantida pela comunidade encontra sua verdade no pensamento futuro. Em outros termos, com o passar do tempo, a opinião alcançada, integrada num processo de raciocínio, manter-se-á condizente com as sensações originadas do processo de observação.

É evidente que a busca da verdade não se coaduna com um processo intuitivo, mas com um processo mediativo, no qual subjaz o papel da comunidade a conferir verdade às crenças alcançadas. Nesse caso, a semioticidade do processo de conhecimento se realiza no interior da comunidade, a qual funciona como "sujeito" do processo. Isso quer dizer que o pensamento não pertence a um eu, individual e rígido, mas é o resultado da semiose, intrínseca à comunidade.

Em relação ao caráter semiótico do eu, lemos em Silveira (1988, p.169):

Aceita-se ou não a interpretação legada pelo passado e determina-se novamente um programa de conduta para o futuro. 0 eu não é então uma unidade perfeita e irredutível. Ele é estruturalmente dicotômico e só se unifica mediante o signo, num diálogo do eu presente que surge no fluxo do tempo com um eu passado, herdeiro de toda tradição, a qual pretende ele preservar. Todo pensamento, na medida em que se constitui no confronto com a alteridade do eu passado, mediante o signo, é dialógico.

0 eu se apresenta, pois, como um processo histórico, resultado de um feixe de informações amalgamadas pela tradição. 0 eu presente, assim como o signo, somente pode ser interpretado em sua relação com 0 eu passado, ao projetar-se num eu futuro, o qual verificará, com o passar do tempo, a conduta previamente estipulada. Dessa forma, o eu constitui o próprio devir, a unidade na multiplicidade, e só assim pode ser interpretado.

A determinação de um programa de conduta, a ser cumprido pelo eu que surge no tempo, é o resultado da intepretação do passado, que carrega o peso das determinações já cumpridas pela comunidade. Esta última, ao intepretar o signo como uma mensagem futura, pode ou não repetir o programa recebido pelo passado. Em todo caso, a verdade de tal relação temporal reside no futuro, nos resultados dos experimentos, realizados pela comunidade de seres que pensam por meio de signos.

O signo, visto dessa perspectiva, é essencialmente social, já que só 
pode ser interpretado no seio de uma comunidade. A tradição, ao cristalizá-lo, propondo-o como um mero nome a designar um objeto, não apreende a real idade como um todo, incidindo numa conduta repetitiva, solipsista e, portanto, neurótica. A noção peirceana contraria essa posição, apresentando o processo próprio da realidade, o qual é verdadeiramente real por resultar da investigação de toda a comunidade.

\section{Conclusões}

Procuramos mostrar que o processo de conhecimento é intrinsecamente semiótico. E que tal pocesso se distingue dos mantidos pela tradição, denominados por Peirce de nominalistas, por permitir que se apreenda a totalidade da realidade. Na visão peirceana, prova-se a inutilidade da divisão fenômeno/coisa-em-si, que restringe 0 alcance da razão teórica, limitando, conseqüentemente, 0 alcance de uma inteligência ávida por aprender. Ao tratar a realidade como semiose, estruturalmente sígnica, Peirce rompe com a tradição, conferindo ao conhecimento um caráter processual, mostrando, com isso, que não há limites para uma mente que evolui com o tempo.

Para que o conhecimento alcance sua meta, expandindo constantemente sua capacidade representativa, com o passar do tempo, mostramos que a semiose não se realiza no âmbito do indivíduo, rompendo sua visão processual, mas é própria de uma comunidade de seres pensantes, a qual tem, como tarefa, conferir verdade às nossas opiniões, conduzindo a investigação para um futuro indefinido. Percebe-se logo que esse processo não caberia ao indivíduo isolado levar adiante. Com isso, portanto, esclarecemos 0 aspecto social do signo-pensamento.

Por fim, podemos dizer que a discussão realizada por nós tem a pretensão de fornecer subsídios para se pensar o papel de Peirce no seio da chamada modernidade, discussão tão em voga nos dias atuais. Com a transformação efetuada na coluna dorsal da doutrina kantiana, ao mesmo tempo que golpeia o pensamento cartesiano, avatar do pensamento moderno, Peirce nos instiga a pensar o seu lugar dentro das discussões atuais, das quais se aproximam pensadores como Habermas, Apel, Derrida, Rorty, dentre outros. Esse é um problema instigante, mas que apenas sugerimos, já que a discussão em torno do pensamento de Peirce, inevitavelmente, nos conduz a ele.

BORTOLOTTI, R. G. The temporal and social status of the sign. Trans/Form/ Ação (São Paulo), v.21-22, p.165-179, 1998-1999. 
- ABSTRACT: This paper has as its objective to show how the knowledge process occurs in a triadic structure whose characteristics cannot prescind either of temporality or its social aspect. Would it not be so in accordance with the subjacent dualism in the traditionals of theories, the scope of knowledge would be itself limited by the inevitability the appeal to a thingin-itself.

- KEYWORDS: Cognition; knowledge; sign; thought; meaning; community; semiosis.

\section{Referências bibliográficas}

APEL, K. O. Charles S. Peirce: from pragmatism to pragmaticism. Amherst: University of Massachutts Press, 1981.

GALLIE, W. B. Peirce and pragmatism. Westport: Greenwood Press, 1975.

HARTSHORNE, C. et al. Collected papers of Charles Sanders Peirce. Cambridge: Harvard University Press, 1931-1935 e 1958. 8v.

M URPHEY, M. G. The development of Peirce's philosophy. Cambridge: Harvard University Press, 1961.

SILVEIRA, L. F. B. da. Semiótica peirceana e produção poética. Trans/Form/ Ação, (São Paulo) n.6, p.13-23, 1983.

. 0 caráter dialógico e social do signo e do pensamento em Peirce. Trans/Form/A ção, (São Paulo) n.2, p.23-9, 1988.

PEIRCE. C. S. Semiótica e filosofia. São Paulo: Cultrix, 1972. . Semiótica. São Paulo: Perspectiva, 1974.

- RESUM 0: Neste artigo, propõe-se uma configuração possível para a transição histórico-filosófica de temas investigados no domínio da metamatemática 